\title{
A role for BRCAI in sporadic breast cancer
}

\author{
JA Fraser 1,4, JR Reeves',4, PD Stanton', DM Black², JJ Going ${ }^{3}$, TG Cooke' and JMS Bartlett*,' \\ 'University Department of Surgery, Glasgow Royal Infirmary, 10 Alexandra Parade, Glasgow G3I 2ER, UK; '2Beatson Institute for Cancer Research, \\ Switchback Road, Bearsden, Glasgow, Scotland, UK; ${ }^{3}$ Department of Pathology, Glasgow Royal Infirmary, 10 Alexandra Parade, Glasgow G3I 2ER, UK
}

To test the hypothesis that altered expression of BRCAI protein may play an important role in sporadic breast cancer development, 50 randomly selected primary breast cancers (frozen sections, 5 years' median follow-up) were immunolabelled with two monoclonal BRCAI antibodies (MSIIO and MSI3). MSIIO labelling was exclusively nuclear showing no relation to outcome or tumour pathology. Western blotting demonstrated crossreactivity, suggesting antibody nonspecificity. MSI 3 labelling was predominantly cytoplasmic. Intense labelling predicted decreased overall survival $(P=0.012)$, disease-free survival $(P=0.029)$, oestrogen receptor negativity $(P=0.0004)$ and $c$-erbB-2 overexpression $(P=0.006)$. Western blotting detected a IIO kDa molecule consistent with BRCAI $\Delta \mathrm{l}$ lb splice variant. BRCAI protein is postulated to function as a tumour suppressor. We demonstrate cytoplasmic localisation in sporadic breast cancer suggesting excess $\Delta \mathrm{I}$ l b splice variant production, reduced production of full-length BRCA I and thus postulate reduced tumour suppressor activity. BRCAI protein appears to have a significant role in both sporadic and hereditary breast cancers.

British Journal of Cancer (2003) 88, 1263-1270. doi:10.1038/sj.bjc.6600863 www.bjcancer.com

(c) 2003 Cancer Research UK

Keywords: BRCAI protein; sporadic breast cancer; immunohistochemistry

Approximately $90 \%$ of extensive breast and/or ovarian cancer families have loss of function germline mutations in the tumour suppressor genes BRCA1 or BRCA2 (17q21 and 13q12-q13, respectively). Germline mutations in $B R C A 1$ account for about $3 \%$ of all breast cancers, with a further $2 \%$ resulting from mutations in BRCA2. Breast cancer patients with mutated BRCA1 frequently demonstrate loss of the corresponding wild-type allele (Cornelis et al, 1995). Fibroblasts expressing BRCA1 antisense RNA, with correspondingly low levels of endogenous BRCA1 protein, display accelerated growth and higher tumorigenicity in nude mice than their control counterparts (Rao et al, 1996). Retroviral transfection of wild-type BRCA1 inhibits growth of breast and ovarian cancer cells in vitro but not those derived from colon or lung (Holt et al, 1996). Since these cell lines are raised from sporadic cancers, these data provide strong support for a role for BRCA1 in sporadic breast cancer. Mutant BRCA1 transfection does not inhibit breast cancer cell growth; ovarian cancer cell growth is unaffected by $5^{\prime}$ but inhibited by $3^{\prime}$ BRCA1 mutations (Holt et al, 1996). In nude mice, MCF-7 breast cancer tumour growth is inhibited by transfection with wild-type but not mutant BRCA1 (Holt et al, 1996). Thus, BRCA1 clearly has an important role in the control of breast neoplasias of sporadic origin.

Wild-type BRCA1 binds to a number of cellular proteins involved in cell cycle regulation including the DNA repair protein Rad51, the tumour suppressor p53, RNA polymerase II holoenzyme, RNA helicase A, CtBP-interacting protein, c-myc, BARD1, BRCA2 protein, etc. BRCA1 is postulated to mediate the

\footnotetext{
*Correspondence: Dr JMS Bartlett; E-mail: j.m.bartlett@clinmed.gla.ac.uk ${ }^{4}$ Contributed equally to this work.

Received 13 May 2002; revised 28 November 2002; accepted 2 December 2002
}

involvement of these proteins in DNA repair, transcriptional transactivation and cell cycle control by acting as a converging vehicle for protein association (Scully et al, 1997a; Anderson et al, 1998; Yu et al, 1998; IrmingerFinger et al, 1999). By affecting BRCA1 protein tertiary structure, BRCA1 mutations may thus disrupt complex associations precipitating dysregulation of cellular functions and eventual progression to malignancy.

BRCA1 germline mutations have been described in only a handful of sporadic breast cancer cases (Futreal et al, 1994; GarciaPatino et al, 1998) where they are likely to represent de novo mutations. No somatic $B R C A 1$ gene mutations have been identified without simultaneous germline mutations, unlike ovarian cancer, where single somatic BRCA1-truncating mutations have been identified (Merajver et al, 1995). BRCA1 protein products may however have an important role in the development of sporadic breast cancers as shown by transfection studies. Increasing evidence exists that abnormal BRCA1 expression plays a key role in nonhereditary cases, with messenger RNA levels being higher within normal breast epithelium and noncomedo in situ breast disease than in cases of sporadic invasive cancer (Thompson et al, 1995). Methylation of cytosine residues is a well-recognised explanation for reduced gene expression when no gene mutations or $\mathrm{LOH}$ is present (methylation silencing). Indeed, aberrant methylation of the BRCA1 CpG island promoter at the $5^{\prime}$ end of the BRCA1 gene has been described and is associated with significantly reduced levels of BRCA1 mRNA (Rice et al, 1998), supporting this hypothesis.

With the recent development of BRCA1-specific antibodies (Chen et al, 1995; Scully et al, 1996), immunohistochemical analysis of tumours is now possible. We have studied 50 randomly selected primary breast cancers by immunohistochemistry using MS110 and MS13 monoclonal antibodies to investigate the relation of BRCA1 expression to pathological, biological and survival parameters. 


\section{METHODS}

\section{Patients}

Frozen tumour tissue was obtained from 50 randomly selected primary operable breast cancer cases treated in Glasgow Royal Infirmary from 1984 to 1993 . Ages ranged from 40 to 77 years (mean age 60.85) at the time of surgery. Pathology confirmed 47 ductal, two medullary and one lobular carcinoma. Patients were followed up in a dedicated breast clinic (median follow-up 5 years). Follow-up was dated to the last documented clinic visit with all recurrences being confirmed by clinical investigation and, where appropriate, pathology. Conventional pathological data were collected (Table 1). Mortality data were cross-referenced with the regional cancer registry. Normal breast tissue was obtained from seven patients undergoing reduction mammoplasty for use as a negative control.

\section{Tissue culture}

MCF-7, SKOV-3, ZR75-1 and BT20 cells were grown in RPMI and MDA-MB-361, MDA-MB-453, SKBR3 and BT474 cells in DMEM, both supplemented with $10 \%$ foetal bovine serum (cell lines available from the American Type Cell Culture Collection). Cells were cultured in a $95 \%$ air, $5 \% \mathrm{CO}_{2}$ humidified atmosphere at $37^{\circ} \mathrm{C}$. Cells were grown to near confluence in $175 \mathrm{~cm}^{2}$ flasks, harvested by scraping and centrifugation at $100 \mathrm{~g}$, and resuspended in $10 \mathrm{ml}$ of PBS (10 mM sodium phosphate, $140 \mathrm{~mm}$ sodium chloride $\mathrm{pH}$ 7.4). Cells were pelleted at $300 \mathrm{~g}$ and cell pellets were stored in liquid nitrogen prior to immunohistochemistry.

\section{Cell fractionation and lysate preparation}

Total protein lysates were prepared from $70-100 \%$ confluent cells. Cells were recovered by incubation with $0.125 \% \mathrm{w} \mathrm{v}^{-1}$ trypsin, resuspended in RPMI supplemented with 10\% FCS, and washed with PBS prior to lysis in modified RIPA buffer (PBS containing $1 \%$ Triton X-100, $0.1 \%$ SDS and a cocktail of protease inhibitors: $100 \mu \mathrm{g} \mathrm{ml}^{-1}$ phenylmethylsulphonyl fluoride (PMSF), $10 \mu \mathrm{g} \mathrm{ml}^{-1}$

Table I Relation of MSIIO and MSI3 immunostaining to pathology $\left(\chi^{2}\right)$

\begin{tabular}{|c|c|c|c|c|c|}
\hline & \multirow[b]{2}{*}{$\mathbf{N}(\%)$} & \multicolumn{2}{|c|}{ [MSIIO] } & \multicolumn{2}{|c|}{ [MSI3] } \\
\hline & & $\chi^{2}$ & $P$ & $\chi^{2}$ & $P$ \\
\hline \multicolumn{6}{|l|}{ Nodal status } \\
\hline Negative & $21(42)$ & 0.246 & 0.62 & 0.027 & 0.87 \\
\hline Positive & $28(56)$ & & & & \\
\hline \multicolumn{6}{|l|}{ Size (mm) } \\
\hline $\mathrm{TI}(<2 \mathrm{I})$ & 16 (33) & & & & \\
\hline T2 $(21-50)$ & $27(56)$ & 0.404 & 0.82 & 0.783 & 0.68 \\
\hline T3 $(>50)$ & $5(10)$ & & & & \\
\hline \multicolumn{6}{|l|}{ Grade } \\
\hline I & $6(12)$ & & & & \\
\hline 2 & $21(42)$ & 0.679 & 0.71 & 4.464 & 0.11 \\
\hline 3 & $23(46)$ & & & & \\
\hline \multicolumn{6}{|c|}{ Oestrogen receptor } \\
\hline Negative & $22(48 \%)$ & 2.14 & 0.14 & 12.54 & 0.0004 \\
\hline Positive & $24(52 \%)$ & & & & \\
\hline \multicolumn{6}{|l|}{$N P I$} \\
\hline I $(<3.4)$ & 7 (|4\%) & 0.860 & 0.651 & 0.598 & 0.742 \\
\hline $2(3.4 I-5.4)$ & $28(56 \%)$ & & & & \\
\hline $3(>5.4)$ & $12(24 \%)$ & & & & \\
\hline
\end{tabular}

leupeptin, $10 \mu \mathrm{g} \mathrm{ml}^{-1}$ pepstatin, $20 \mu \mathrm{g} \mathrm{ml}^{-1}$ aprotinin and $10 \mathrm{mmol}$ benzamidine). Lysates were passed through a 28-gauge needle, rotated for $20 \mathrm{~min}$ at $4{ }^{\circ} \mathrm{C}$, and then centrifuged at $15000 \mathrm{~g}$ for $20 \mathrm{~min}$ to precipitate insoluble cellular debris. Protein yield was estimated spectrophotometrically at $595 \mathrm{~nm}$ using the Bradford method (Bradford, 1976).

For cell fractionation, $8-12175 \mathrm{~cm}^{2}$ flasks were collected as above, and washed with PBS. Cells were resuspended in $1.5-2 \mathrm{ml}$ hypotonic buffer ( $30 \mathrm{~mm}$ Hepes, $\mathrm{pH} 7.5,5 \mathrm{~mm} \mathrm{KCl,} 1 \mathrm{~mm} \mathrm{MgCl}_{2}$ ) and protease inhibitor cocktail as above. After a 30-min incubation on ice, cells were homogenised with a tight-fitting dounce homogeniser and lysis was monitored by microscopy. An equal volume of NP-40 lysis buffer (10 mM Tris, $\mathrm{pH} 7.4,250 \mathrm{~mm}$ sucrose, $1.0 \mathrm{mM} \mathrm{MgCl}_{2}, 0.1 \% \mathrm{NP}-40$ ) was added to complete lysis. Nuclei were collected by centrifugation at $3000 \mathrm{~g}$, washed twice in NP-40 lysis buffer, and then lysed in modified RIPA buffer. Both nuclear and cytoplasmic fractions were centrifuged at $15000 \mathrm{~g}$ to precipitate insoluble cellular debris.

\section{Tumour protein extraction for immunoblotting}

Tumours were selected from the highest and lowest MS13 scoring groups. Tumour blocks were maintained at $-20^{\circ} \mathrm{C}$ or lower. Dismembranation was achieved by pulsing for $8 \times 1 \mathrm{~min}$ at 2000 cycles $\min ^{-1}$ (Mikro Dismembrator, Braun Biotech International). Chilled modified RIPA buffer $(500 \mu \mathrm{l})$ was added and the mixture pulsed for a further $2 \mathrm{~min}$. The mixture was then mixed for $30 \mathrm{~min}$ at $4{ }^{\circ} \mathrm{C}$ before being centrifuged at $15000 \mathrm{~g}$ to pellet insoluble cellular debris. Protein yield was estimated as previously described. Supernatant was collected and stored frozen as wholecell lysate.

\section{Immunoblotting analysis}

Immunoblotting was performed on breast carcinoma cell lines MCF-7 and SKOV-3 and tumour lysates. In total, $100 \mu \mathrm{g}$ of each cellular protein lysate (whole cell, nuclear or cytoplasmic) was denatured by boiling for $10 \mathrm{~min}$ in Laemmli buffer and then run on $6 \%$ SDS-polyacrylamide gel. Proteins were transferred by electrophoresis at $15 \mathrm{~V}$ for $120-180 \mathrm{~min}$ to Bio-rad Sequi-Blot PVDF membrane using a Biorad semidry blotter. The membrane was blocked in $5 \%$ nonfat milk, $10 \%$ sheep serum in Tris buffered

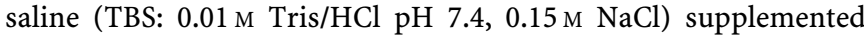
with $0.05 \%$ Tween 20 (TTBS-milk) overnight at $4{ }^{\circ} \mathrm{C}$. The membrane was incubated for $2 \mathrm{~h}$ at room temperature with primary antibody in TTBS-milk (antibody concentration of $2 \mu \mathrm{g} \mathrm{ml}^{-1}$ in the case of both MS13 and MS110). Washes were performed in TTBS. Secondary antibody was peroxidase- labelled, affinity purified sheep anti-mouse IgG (Sigma Chemical Company) at a dilution of $1: 5000$ applied for $40 \mathrm{~min}$. The peroxidase signal was developed with ECL as per the manufacturer's directions (Amersham International, Amersham, UK).

\section{Immunohistochemistry}

Frozen section immunohistochemistry was performed as previously reported (Reeves et al, 1996). Briefly, $5 \mu \mathrm{m}$ acetone-fixed cryostat sections of tumour, normal breast tissue or cell line pellets were labelled with monoclonal anti-BRCA1 antibodies MS110 and MS13 (Scully et al, 1996) (BRCA1 Ab1 and Ab2, respectively, supplied by Oncogene Research Products, Calbiochem Novabiochem (UK) Ltd, Nottingham, UK). All steps were performed at room temperature in a humidified cabinet. Endogenous biotin was suppressed prior to immunohistochemical labelling, and nonspecific binding was further blocked by preincubating the sections with $25 \%$ of both rabbit and human serum in PBS. Sections were incubated with primary antibody for $2 \mathrm{~h}$ (antibody concentration of $1 \mu \mathrm{g} \mathrm{ml}^{-1}$ in both cases). Antigen was detected with biotinylated 
rabbit anti-mouse immunoglobulins (Dako, High Wycombe, UK) applied for $30 \mathrm{~min}$ at a dilution of $1: 400$ prior to using the streptavidin-biotin - peroxidase complex detection system (Dako, High Wycombe, UK) according to the manufacturer's instructions. In all, $10 \%$ each of human and rabbit serum were included in the primary and secondary antibody diluent. The peroxidase signal was developed with a 10 -min exposure to $0.07 \%$ nickel chloride, $0.025 \%$ diaminobenzidine tetra hydrochloride and $0.01 \%$ hydrogen peroxide producing a black precipitate. The nuclei were counterstained with safranin before dehydration and mounting. Negative controls were performed on parallel sections by using isotypematched nonimmune immunoglobulin in place of the primary antibody.

To confirm the specificity of the MS13 and MS110 antibody, the epitope to which they had been raised was synthesised. This protein fragment competitively inhibited antibody binding in tissues known to give positively labelled results.

\section{Immunohistochemical scoring}

Two different methods of immunohistochemical scoring were utilised because of the differences in staining patterns. MS110 staining was nuclear and so a conventional scoring method was employed, estimating the percentage of labelled tumour cell nuclei. MS13 staining was however cytoplasmic and thus a histoscore was calculated from the sum of $(1 \times \%$ weakly positive $)+(2 \times \%$ moderately positive $)+(3 \times \%$ strongly positive $)$ with a maximum of 300 . The mean of the two observers' scores was used for analysis.

\section{Statistics}

BRCA1 scores for each antibody were treated as binary variables (above or below the median score). Tumours with higher than median and lower than median MS110 or MS13 scores were assessed in relation to the following biological variables: nodal status, Bloom and Richardson tumour grade, oestrogen receptor status and tumour size using $\chi^{2}$ analysis and with the continuous variable age using the Mann-Whitney test. Life table analysis of overall and disease-free survival was performed using KaplanMeier estimates and log-rank tests. Spearman's rank correlation was used for direct comparison of the scores with the two antibodies on the tumour samples.

Analysis of agreement for each set of measurements was conducted using the methods of Bland and Altman (1986, 1999). The mean difference between measurements was obtained and 95\% confidence intervals for the mean calculated. If these confidence intervals span zero, it is judged that there is no systematic bias measurements in between observers.

\section{RESULTS}

\section{MS110 immunohistochemistry}

In histologically normal epithelium from breast reduction specimens MS110 revealed nuclear labelling in approximately $1-5 \%$ of epithelial cells (Figure 1A). The same staining pattern was present in cell lines (nuclear labelling range $2-50 \%$ ) (Figure $1 \mathrm{D}$ and Table 2) and in sporadic breast tumour specimens (nuclear labelling ranging $\leqslant 1-60 \%$ ) (Figures $1 \mathrm{G}, \mathrm{J}$ ). No labelling was present in the parallel control sections (Figures 1C, F, I, L). Of the two independent observers' (JRR and JJG) scores (Figure 2A), JRR's estimations of the proportion of MS110-labelled nuclei ranged from 1 to $70 \%$ with a median of $10 \%$, whereas JJG's scores ranged from 0 to $50 \%$ with a median of $5 \%$. For statistical analysis, the mean of both observers' scores was calculated and categorised on a binary basis on either side of the median.
Comparison of MS110 scores between observers produced a mean difference of 5.30 . The $95 \%$ confidence intervals for the mean do not include zero $(2.18-8.42)$, reflecting a small systematic bias in the scoring $(P=0.001)$. Nonetheless, the Pearson correlation coefficient $(0.72, P=0.0001)$ and the $95 \%$ limits of agreement span a sufficiently small range $(-16.68$ to 27.28$)$ to enable the two observers' scores to be deemed comparable. Similarly, comparison of MS13 histoscores produced a mean difference of -13.52 . The $95 \%$ confidence intervals for the mean are -22.65 to -4.39 . Once again the confidence intervals do not include zero, reflecting a systematic bias in the histoscoring. The Pearson correlation coefficient is $0.922(P=0.0001)$ and although the $95 \%$ limits of agreement ( -77.75 to 50.71$)$ are broad, given the histoscore range of $0-300$, they can be considered to demonstrate acceptable interobserver agreement. Again the mean of the two observers' scores was used for analysis.

\section{MS13 immunohistochemistry}

MS13 antibody immunostaining pattern was strong, cytoplasmic and always confined to the ductal and terminal ductal lobular unit epithelial cells in histologically normal breast tissue (Figure 1B). Within all cell lines (Figure 1E and Table 2) and sporadic breast tumour samples (Figures $1 \mathrm{H}, \mathrm{K}$ ), the signal was cytoplasmic with mean histoscores ranging from 0 to 140 and 0 to 257.5, respectively. Parallel control sections of normal and malignant breast samples, and cell lines demonstrated no staining (Figures 1C, F, I, L). Again the mean of the two observers' scores was used for analysis (Figure 2B). JRR's histoscores ranged from 0 to 270 with a median of 50, and JJG's ranged from 0 to 260 with a median of 66. As above, the mean of the two observers' scores was calculated and categorised on a binary basis on either side of the median.

\section{BRCA1 expression in relation to tumour pathology}

Oestrogen receptor positive tumours were significantly more likely to have lower MS13 histoscores (mean histoscore 87.2) than their oestrogen receptor negative counterparts (mean histoscore 136.8) $(P=0.0004)$. No significant relation $(P \geqslant 0.05)$ was demonstrated between the proportion of MS110 positive nuclei or MS13 histoscore and patient age, nodal status, tumour size, tumour grade or the Nottingham Prognostic Index (Galea et al, 1992), which combines the prognostic information given by nodal status, tumour size and tumour grade (Table 1).

A relation was sought between MS110 and MS13 staining patterns and c-erbB-2 and epidermal growth factor receptor data previously published by this group (Reeves et al, 1996; Robertson et $a l, 1996)$. A strong relation was evident between intensity of MS13 labelling and increased c-erbB-2 expression $(P=0.006)$. This was confirmed by fluorescent in situ hybridisation (FISH) where high MS13 scorers correlated with the FISH positive expressors $(P=0.03)$ (in-house data) (Bartlett et al, 2001). No relation was demonstrated between epidermal growth factor receptor (EGFR) and either antibody score. Direct comparison of paired MS13 and MS110 histoscores was performed and demonstrated no relation.

\section{BRCA1 expression in relation to outcome}

Univariate survival analysis was carried out for both sets of data using Kaplan-Meier estimates and log-rank tests. MS110 immunostaining did not relate to disease-free $(P=0.62)$ or overall survival $(P=0.62)$ in this group. However, high MS13 histoscores were associated significantly with both a shorter overall survival $(P=0.012 ;$ Figure $3 \mathrm{~A})$ and disease-free interval $(P=0.029$; Figure $3 \mathrm{~B})$. 

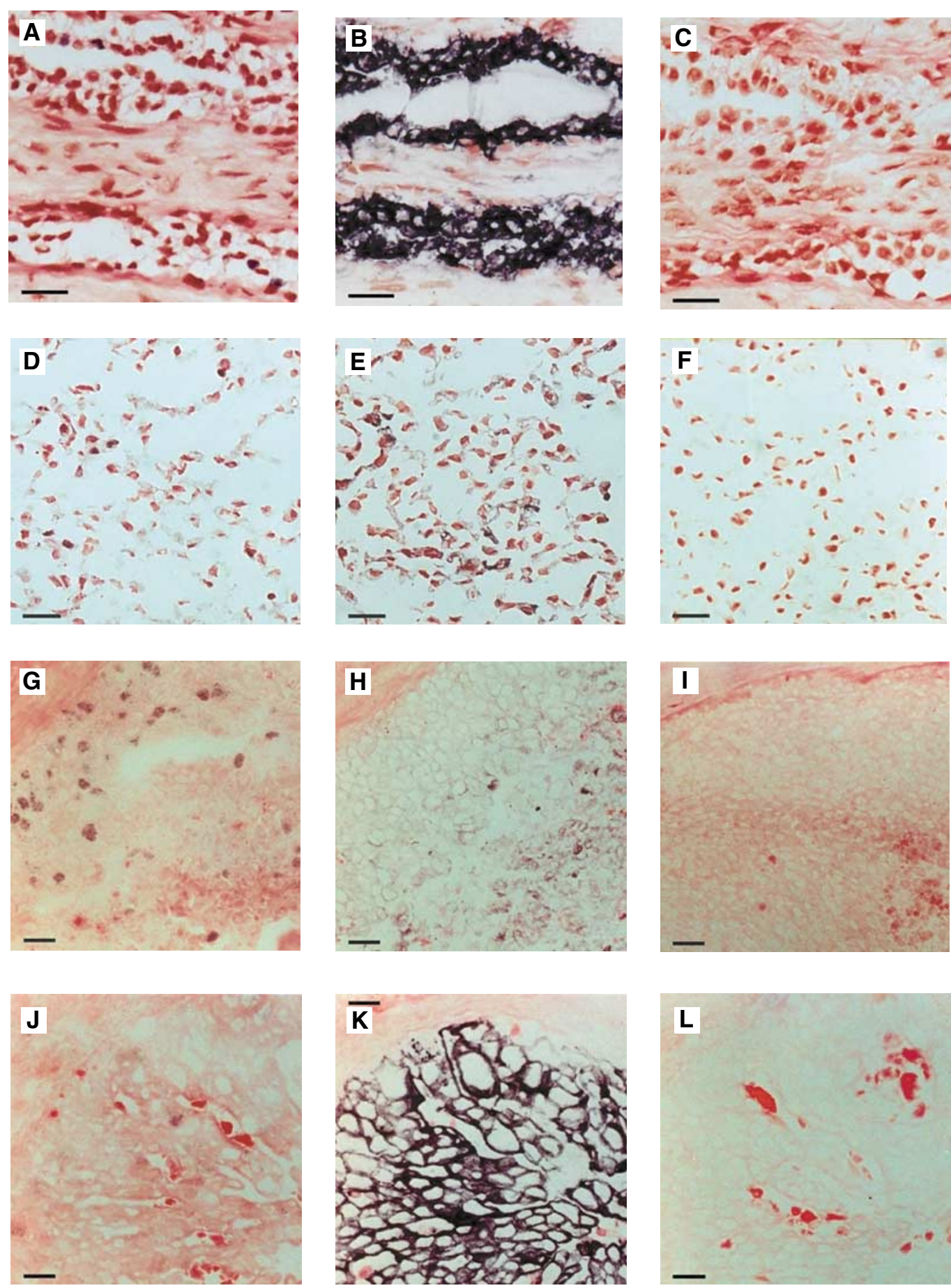

Figure I (A) Normal breast epithelium labelled with MSI I0 demonstrating nuclear staining of approximately I - 5\% of tumour nuclei; (B) parallel section stained with MSI 3 demonstrating strong cytoplasmic staining of the ductal and terminal ductal lobular unit; (C) parallel control section; (D) SKBR-3 cell line section labelled with MSIIO showing nuclear labelling; (E) a parallel section stained with MSI3 demonstrating cytoplasmic staining (histoscore I40); (F) parallel control section; (G) sporadic breast cancer section labelled with MSI I0 (estimated 30\% labelling of the tumour nuclei); (H) parallel section stained with MSI3 (mean histoscore 80); (I) parallel control section; (J) sporadic breast cancer section labelled with MSI I0 (estimated 5\% labelling of the tumour nuclei); (K) parallel section stained with MSI3 (mean histoscore 270); (L) parallel control section. Control sections were labelled with isotype-matched nonimmune immunoglobulin in place of the primary antibody. Bars $=20 \mu \mathrm{M}$.

\section{Competitive inhibition of BRCA1 labelling}

Differing concentrations of the 304 amino-acid protein fragment were used. Staining remained present at lower concentrations $\left(\leqslant 53 \mu \mathrm{g} \mathrm{ml}^{-1}\right)$, but disappeared as epitope concentrations were increased (absent at $\geqslant 70 \mu \mathrm{g} \mathrm{ml}^{-1}$ ).

\section{Western blotting analysis}

Western blots were carried out to ensure that both antibodies used for immunohistochemistry were sensitive and specific for BRCA1.

MS110 detected both 220 and $110 \mathrm{kDa}$ bands in the whole cell and the nuclear fractions of both cell lines tested as well as 
Table 2 Immunohistochemical data for cell lines

\begin{tabular}{lrc}
\hline Cell line/tumour & MSI I $\%$ +ve nuclei & MSI3 histoscore \\
\hline MDA-MB-36I & 25 & 10 \\
MDA-MB-453 & 2 & 125 \\
ZR75-I & 5 & 0 \\
MCF7 & 15 & 0 \\
SKBR3 & 50 & 140 \\
BT20 & 20 & 80 \\
BT474 & 40 & 25 \\
SKOV-3 & 40 & 5 \\
\hline
\end{tabular}

A

Frequency distribution of MS13 labelling

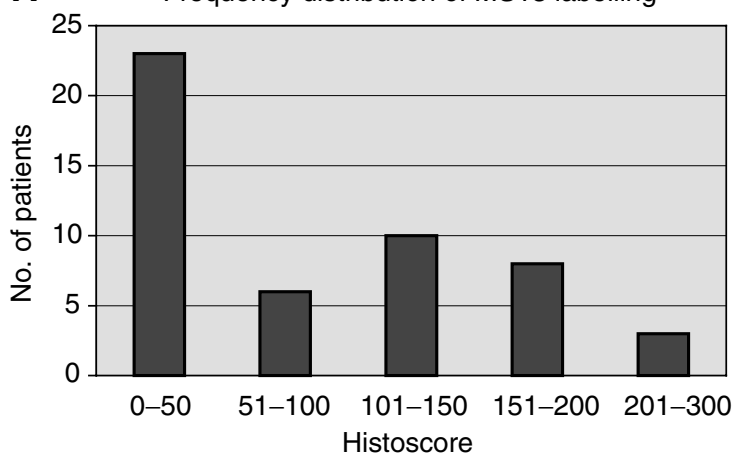

B

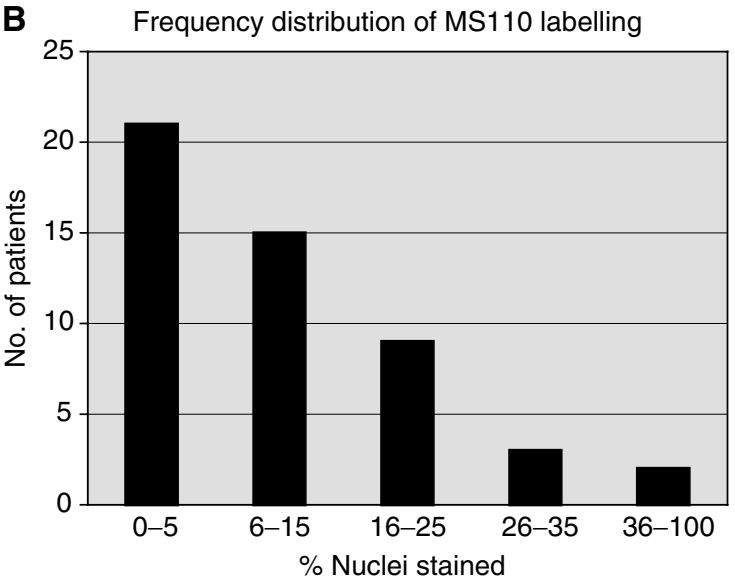

Figure 2 Frequency histograms demonstrating the distribution of $(\mathbf{A})$ MSI I 0 labelling and (B) MSI 3 labelling in 50 randomly selected sporadic breast cancers.

numerous other bands, suggesting that, although detecting the fulllength and splice variant of BRCA1, MS110 crossreacts with a number of other proteins (Figure 4).

MS13 detected a $110 \mathrm{kDa}$ band in the whole cell and cytoplasmic fractions of the cell lines tested, with a faint shadow also in the nuclear fraction, consistent with it detecting the $\Delta 11 \mathrm{~b}$ splice variant (Figure 4). A faint $220 \mathrm{kDa}$ band could also be detected in whole-cell lysates.

Low- and high-scoring tumours from the MS13 immunostained group were selected and protein was extracted for Western blotting. This confirmed MS13 to label a $110 \mathrm{kDa}$ molecule in the tumour setting, consistent with the cell line Western blot findings (Figure 5). MS110 detected numerous bands ranging from 286 to $54 \mathrm{kDa}$, an identical picture to that seen with the cell lines.
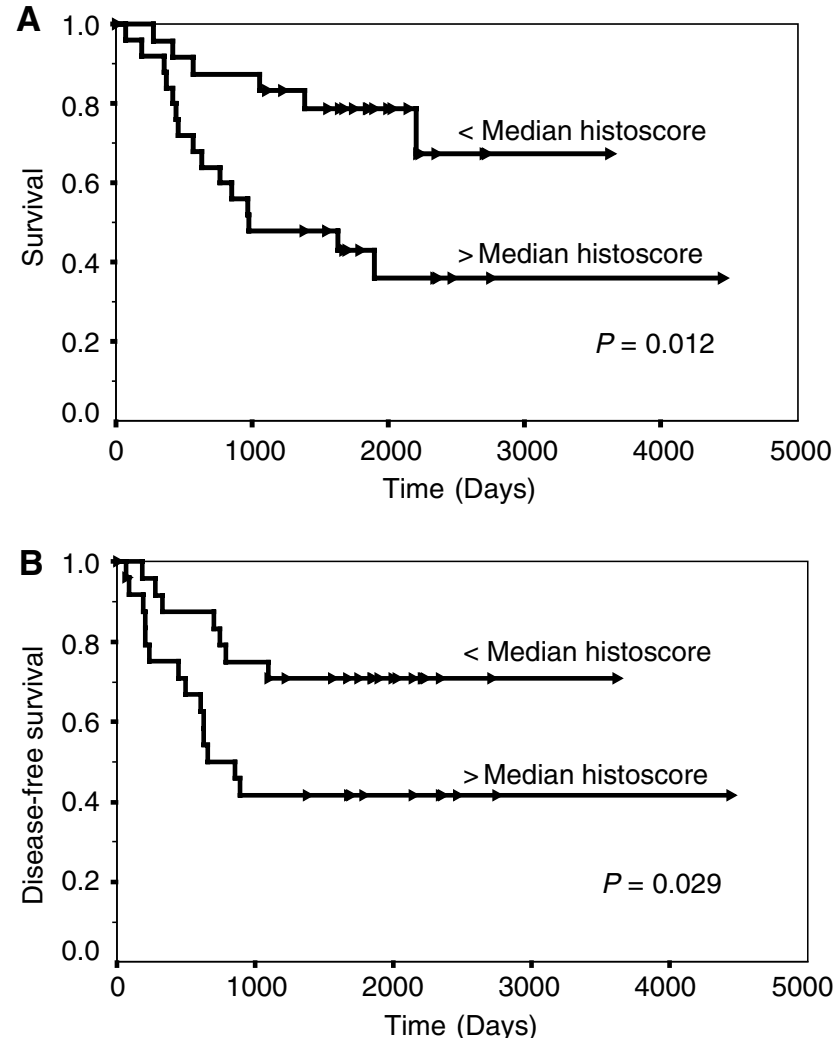

Figure 3 (A) Survival curve analysis (from all causes) according to low and high immunohistochemical labelling with the MSI 3 antibody and (B) disease-free survival curve analysis (local and distant recurrence). Arrowheads indicate censored events (Kaplan-Meier estimates and log-rank tests).

\section{DISCUSSION}

The BRCA1 gene and its protein products have been the subject of intensive investigation over recent years because of their proven role in hereditary and putative role in sporadic human breast and ovarian cancer. Controversy concerning the subcellular localisation of the BRCA1 protein has abounded, with it being reported as nuclear (Scully et al, 1996), nuclear in normal but cytoplasmic in breast and ovarian carcinoma cells (Chen et al, 1995), membrane associated on the cytoplasmic aspect of nuclear invaginations (Coene et al, 1997), or a secreted growth inhibitor (Holt et al, 1996; Jensen et al, 1996). This debate has been fuelled by concerns regarding the specificity of the monoclonal antibodies available for BRCA1 detection (Wilson et al, 1996; Thakur et al, 1997).

MS110 and MS13 are monoclonal antibodies raised to the Nterminal 304 amino acids of BRCA1 (Scully et al, 1996) supposedly specific to BRCA1. Data presented here demonstrate different staining patterns for these two antibodies in frozen breast cancer sections, suggesting that these antibodies recognise distinct protein species or isoforms of the same protein. Staining with both antibodies was successfully competitively inhibited using the 304 amino-acid N-terminus to which the antibodies had been raised, confirming the ability of MS110 and MS13 to detect the BRCA1 N-terminus but not ruling out crossreactivity with confounding proteins.

Western blot analysis, following full optimisation of the conditions, demonstrated MS13 to be specific for a $110 \mathrm{kDa}$ protein consistent with the previously reported $\Delta 11 \mathrm{~b}$ splice variant of BRCA1 (Wilson et al, 1997), with occasionally a $220 \mathrm{kDa}$ molecule faintly demonstrable in cell extracts. No crossreactivity 


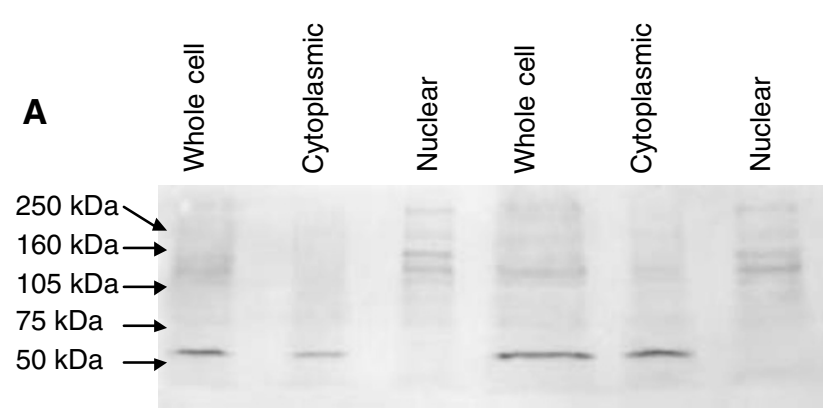

B

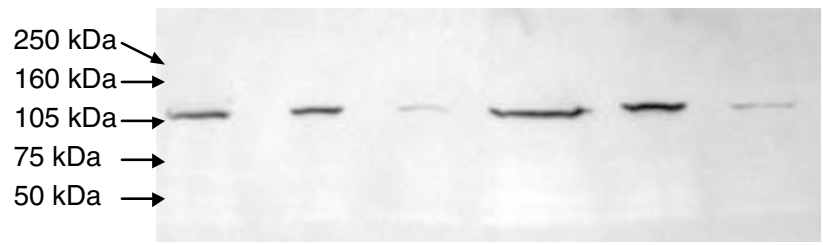

Figure 4 SKOV-3 whole, cytoplasmic and nuclear fractions (I00 $\mu \mathrm{g}$ aliquots lanes I - 3, and $200 \mu \mathrm{g}$ aliquots lanes 4-6) probed with (A) MSI IO demonstrating multiple bands of various molecular weights and (B) MSI3 demonstrating one band of $110 \mathrm{kDa}$ in the whole cell and cytoplasmic fractions and faintly in the nuclear fraction.

\begin{tabular}{ccc} 
& Tumour A & \multicolumn{2}{c}{ Tumour B } \\
& $100 \mu \mathrm{g} \quad 200 \mu \mathrm{g}$ & $100 \mu \mathrm{g} \quad 200 \mu \mathrm{g}$
\end{tabular}

Figure 5 Sporadic breast cancer tumours (tumour A lanes 1 and 2. tumour B lanes 3 and 4). Whole-cell protein lysate (100 and $200 \mu \mathrm{g}$ aliquots) probed with $\mathrm{MSI} 3$ demonstrating the presence of one detected molecule of I I kDa.

with other protein species was observed. Furthermore, the 304 amino-acid BRCA1 N-terminus was readily identified on Western blot using MS13. In contrast, while MS110 also detected a 110 and a $220 \mathrm{kDa}$ product, numerous other proteins were also detected, suggesting significant crossreactivity with non-BRCA1 protein species. MS110 did, however, also readily identify the 304 aminoacid N-terminus of the BRCA1 protein in Western blot analysis. These data support the conclusion that MS13 is specific for BRCA1 detecting the BRCA1 $\Delta 11 \mathrm{~b}$ splice variant in a highly specific manner, while MS110 lacks specificity in Western analysis. In the light of these findings, staining with the Ab1 antibody cannot be clearly linked with BRCA1 expression.

Previous studies using anti-BRCA1 antibodies have described crossreactivity with various different molecules (Wilson et al, 1996). In this study, EGFR immunohistochemistry was performed in parallel with MS13 and MS110 immunohistochemistry. EGFR staining patterns were entirely distinct from those observed with either MS110 or MS13. Furthermore, although an association was observed between the intensity of MS13 immunostaining and high c-erbB-2 expression, the staining pattern for c-erbB-2 was also distinct from that of MS13. Additionally, two tumours with previously demonstrated c-erbB-2 gene amplification and very high c-erbB-2 protein expression (Reeves et al, 1996; Robertson et al, 1996) were present in the patient cohort and were entirely negative by MS13 immunohistochemistry. These data suggest that MS13 does not crossreact with these members of the type one growth factor receptor family.

The $\Delta 11 \mathrm{~b}$ splice variant lacks the majority of exon 11 (amino acids $263-1365$ ) and the resultant $110 \mathrm{kDa}$ protein lacks the nuclear localisation signal. This protein is thought to accumulate in the cytoplasm (Thakur et al, 1997; Wilson et al, 1997). Synthesis of full-length BRCA1 protein is rapidly followed by translocation to the cell nucleus. Despite Western analysis of MS110 demonstrating crossreactivity with a number of protein species, both nuclear and cytoplasmic in localisation, IHC staining with MS110 is almost exclusively nuclear. Although crossreactivity with a nonBRCA1 nuclear located protein in IHC cannot be excluded. It is probable that the MS110 antibody demonstrates stronger affinity for the full-length protein in its native, full-length form.

Cell fractionation studies described here confirmed the $110 \mathrm{kDa}$ protein species detected by MS13 to be predominantly localised in the cytoplasmic cell fractions, thus confirming the immunohistochemical results. The faint presence of the $110 \mathrm{kDa}$ molecule in the nuclear fraction is likely to represent contamination of the nuclear fraction at the time of preparation. Alternatively, a further as yet unrecognised nuclear localisation signal could exist, allowing some translocation of the $\Delta 11 \mathrm{~b}$ splice variant to the nucleus. Further studies on the subcellular localisation of the $\Delta 11 \mathrm{~b}$ splice variant would be required to address this.

In this study, immunohistochemistry and Western blotting results for MS13 are concordant. The MS110 antibody is clearly nonspecific, and results should not be extrapolated to BRCA1. MS13 staining is also consistent with the lack of a nuclear translocation signal. Hence, three strands of evidence confirm our results to be correct and reproducible under different fixation conditions. Previous work has suggested that MS13 staining is predominantly nuclear and represents the full-length protein (Wilson et al, 1999). However, recent immunoblotting data from the same group (http://www.med.ucla.edu/ora/manuscripts.htm) showed MS13 to detect the $\Delta 11 \mathrm{~b}$ splice variant in the cytoplasm as well as the full-length BRCA1 species in the nucleus. Our failure to detect nuclear MS13 staining may represent lower concentrations of this protein than levels of splice variant detected in the cytoplasm.

A significant relation was demonstrated between MS13 labelling and overall survival $(P=0.012)$ and disease-free survival $(P=0.029)$, with increasing intensity of staining indicating worsening outcome in both situations (Figure 3A, B). Intense MS13 staining was also significantly associated with high c-erbB-2 expression $(P=0.006)$ and oestrogen receptor negativity $(P=0.0004)$, both indicators of a poorer prognosis. Familial breast carcinomas with germline mutations of BRCA1 are frequently associated with absence of c-erbB-2 expression (Lakhani et al, 2002). However, care should be taken in extrapolating findings from cases with mutational alterations to BRCA1 to those with potentially physiologically relevant variations in expression of different isoforms. Our study suggests that sporadic breast cancers with overproduction of the $\Delta 11 \mathrm{~b}$ splice variant are commonly associated with overexpression of c-erbB-2. Oestrogen and progesterone have both previously been reported to induce BRCA1 expression in breast cancer cell lines containing these nuclear hormone receptors (Gudas et al, 1995). Initially thought to be a direct response to oestrogen stimulation, increased BRCA1 expression has now been demonstrated to be a response to the increased DNA synthesis initiated by oestrogen stimulation (Marks et al, 1997). The function of nuclear BRCA1 as a cell cycle checkpoint regulator has, however, been suggested to be a response to DNA aberrations requiring repair rather than a direct response to DNA synthesis itself (Marquis et al, 1995; Scully et al, 
1997b). It is possible that the type I tyrosine kinase growth factor receptor c-erbB-2 induces BRCA1 transcription by a similar pathway. This would suggest that the increase in cell proliferation with associated genetic mutations common to all tumours should cause an increase in BRCA1 transcription and translation. This study would suggest that in sporadic breast cancer cases the overproduced BRCA1 species is the $\Delta 11 \mathrm{~b}$ splice variant.

No function has as yet been ascribed to the cytoplasmically located $\Delta 11 \mathrm{~b}$ splice variant; however, the fact that analyses have shown that elimination of exon 11 by differential splicing also occurs in the mouse (Hakem et al, 1996) is strong evidence that this message may encode a protein of physiological importance. In vivo work has confirmed the $\Delta 11 \mathrm{~b}$ splice variant to be transcribed at physiologically significant levels (Gudas et al, 1995, 1996). Significant data exist suggesting that the $\Delta 11 \mathrm{~b}$ splice variant is functionally distinct from full-length BRCA1 in several respects. (i) As a result of splice elimination of the NLS encoded in exon $11 \mathrm{~b}$, the $\Delta 11 \mathrm{~b}$ protein cannot autonomously translocate to the nucleus. (ii) The BRCA1 $\Delta 11 \mathrm{~b}$ splice variant does not exhibit the cell toxicity apparent with overexpression of the full-length protein in transiently transfected cells. (iii) The $\Delta 11 \mathrm{~b}$ splice variant mRNA has been reported to be differentially reduced or absent in breast and ovarian tumour cell lines relative to exon $11 \mathrm{~b}$ and transcripts with and without exons 9 and 10 (Wilson et al, 1997). All would support a function for the BRCA1 $\Delta 11 \mathrm{~b}$ splice variant distinct to that of full-length BRCA1.

Altering the intracellular localisation of the BRCA1 species may act as an important physiological regulatory mechanism. In the normal setting, DNA synthesis and genetic mutations are relatively low. A correspondingly low level of full-length BRCA1 compared to splice variant would thus be expected as was found in normal breast epithelium in our data. Similarly, an increase in full-length BRCA1 production could be expected to deal with the increased number of genetic mutations occurring in the malignant setting. In sporadic breast cancer however, it appears that an excess of
BRCA1 $\Delta 11 \mathrm{~b}$ splice variant is produced, perhaps signifying the malfunction of this physiological control mechanism.

No significant correlation was observed with any of the other biological or pathological markers studied (nodal status, tumour size, tumour grade), suggesting that increased levels of $\Delta 11 \mathrm{~b}$ splice variant are an independent marker of poor prognosis. This is currently under investigation in a larger cohort of patients in our laboratory.

This study demonstrates that MS13 labelling is associated significantly with poor prognosis. MS13 appears to preferentially label the $\Delta 11 \mathrm{~b}$ splice variant of BRCA1. It would therefore appear that presence of the $\Delta 11 \mathrm{~b}$ splice variant is a strong negative prognostic marker in sporadic breast cancer. These data demonstrate the importance of the BRCA1 regulatory system in sporadic tumours. No significant association between MS13 histoscore and the Nottingham Prognostic Index (Galea et al, 1992) is seen in this series. Although performed in a limited series of cases, we are able to hypothesise from these data that alterations to BRCA1 function, other than inherited mutational changes, may play a significant role in the pathophysiology of breast cancer. We are currently testing this hypothesis in a wider patient cohort to evaluate the potential of MS13 immunohistochemistry as an independent prognostic marker of patient outcome. Should this research confirm our preliminary data, evidence will be provided that BRCA1 is a powerful mediator of sporadic breast cancer aggressiveness.

\section{ACKNOWLEDGEMENTS}

The photographic assistance of Glasgow Royal Infirmary's Medical Illustration Department and the scientific advice of Dr Wilson Angerson (University Department of Surgery, Glasgow Royal Infirmary) are gratefully acknowledged. This work was supported by the Breast Cancer Research Trust and Glasgow Royal Infirmary University Trust Endowments Funds.

\section{REFERENCES}

Anderson SE, Schlegel BP, Nakajima T, Wolpin ES, Parvin JD (1998) Brca1 protein is linked to the RNA polymerase II holoenzyme complex via RNA helicase A. Nat Genet 19: 254-256

Bartlett J, Going J, Mallon E, Watters A, Reeves J, Stanton P, Richmond J, Donald D, Ferrier R, Cooke T (2001) Evaluating HER2 amplification and overexpression in breast cancer. J Pathol 195: 422-428

Bland JM, Altman DG (1986) Statistical methods for assessing agreement between two methods of clinical measurement. Lancet i: 307-310

Bland JM, Altman DG (1999) Measuring agreement in method comparison studies. Stat Methods Med Res 8: 135-160

Bradford MM (1976) A rapid and sensitive method for the quantification of microgram quantities of protein utilising the principle of protein-dye binding. Analyt Biochem 72: 248-254

Chen Y, Chen CF, Riley DJ, Allred DC, Chen PL, Von Hoff D, Osborne CK, Lee WH (1995) Aberrant subcellular localization of BRCA1 in breast cancer. Science 270: 789-791

Coene E, Van Oostveldt P, Willems K, Van Emmelo J, De Potter CR (1997) BRCA1 is localized in cytoplasmic tube-like invaginations in the nucleus. Nat Genet 16: 122 -124

Cornelis RS, Neuhausen SL, Johansson O, Arason A, Kelsell D, Ponder BAJ, Tonin P, Hamann U, Lindblom A, Lalle P, Longy M, Olah E, Scherneck S, Bignon YJ, Sobol H, ChangClaude J, Larsson C, Spurr N, Borg A, Barkardottir RB, Narod S, Devilee P (1995) High allele loss rates at $17 \mathrm{q} 12-\mathrm{q} 21$ in breast and ovarian-tumors from BRCA1-linked families. Genes Chromosomes Cancer 13: 203-210

Futreal PA, Liu QY, Shattuckeidens D, Cochran C, Harshman K, Tavtigian S, Bennett LM, Haugenstrano A, Swensen J, Miki Y, Eddington K, Mcclure M, Frye C, Weaverfeldhaus J, Ding W, Gholami Z, Soderkvist P, Terry L, Jhanwar S, Berchuck A, Iglehart JD, Marks J, Ballinger DG, Barrett JC, Skolnick MH, Kamb A, Wiseman R (1994) BRCA1 mutations in primary breast and ovarian carcinomas. Science 266: 120-122
Galea MH, Blamey RW, Elston CE, Ellis IO (1992) The Nottingham prognostic index in primary breast-cancer. Breast Cancer Res Treat 22: $207-219$

Garcia-Patino E, Gomendio B, Provencio M, Silva JM, Garcia JM, Espana P, Bonilla F (1998) Germ-line BRCA1 mutations in women with sporadic breast cancer: clinical correlations. J Clin Oncol 16: 20

Gudas JM, Li T, Nguyen H, Jensen D, Rauscher FJ, Cowan KH (1996) Cellcycle regulation of BRCA1 messenger RNA in human breast epithelial cells. Cell Growth Diff 7: 717-723

Gudas JM, Nguyen H, Li T, Cowan KH (1995) Hormone-dependent regulation of BRCA1 in human breast-cancer cells. Cancer Res 55: 4561 4565

Hakem R, delaPompa JL, Sirard C, Mo R, Woo M, Hakem A, Wakeham A, Potter J, Reitmair A, Billia F, Firpo E, Hui CC, Roberts J, Rossant J, Mak TW (1996) The tumor suppressor gene BRCA1 is required for embryonic cellular proliferation in the mouse. Cell 85: $1009-1023$

Holt JT, Thompson ME, Szabo C, Robinsonbenion C, Aarteaga CL, King MC, Jensen RA (1996) Growth-retardation and tumor-inhibition by BRCA1. Nat Genet 12: 298-302

IrmingerFinger I, Siegel BD, Leung WC (1999) The functions of breast cancer susceptibility gene 1 (BRCA1) product and its associated proteins. Biol Chem 380: $117-128$

Jensen RA, Thompson ME, Jetton TL, Szabo CI, Vandermeer R, Helou B, Tronick SR, Page DL, King MC, Holt JT (1996) BRCA1 is secreted and exhibits properties of a granin. Nat Genet 12: 303-308

Lakhani SR, Van De Vijver MJ, Jacquemier J, Anderson TJ, Osin PP, McGuffogg L, Easton DF (2002) The pathology of familial breast cancer. Predictive value of immunohistochemical markers oestrogen receptors, progesterone receptors, HER-2, and $\mathrm{p} 53$ in patients with mutations in BRCA1 and BRCA2. J Clin Oncol 20: 2310-2318 
Marks JR, Huper G, Vaughn JP, Davis PL, Norris J, McDonnell DP, Wiseman RW, Futreal PA, Iglehart JD (1997) BRCA1 expression is not directly responsive to estrogen. Oncogene 14: 115-121

Marquis ST, Rajan JV, Wynshawboris A, Xu TJ, Yin GY, Abel KJ, Weber BL, Chodosh LA (1995) The developmental pattern of BRCA1 expression implies a role in differentiation of the breast and other tissues. Nat Genet 11: $17-26$

Merajver SD, Pham TM, Caduff RF, Chen M, Poy EL, Cooney KA, Weber BL, Collins FS, Johnston C, Frank TS (1995) Somatic mutations in the BRCA1 gene in sporadic ovarian-tumors. Nat Genet 9: 439-443

Rao VN, Shao NS, Ahmad M, Reddy ESP (1996) Antisense RNA to the putative tumor suppressor gene BRCA1 transforms mouse fibroblasts. Oncogene 12: $523-528$

Reeves JR, Going JJ, Smith G, Cooke TG, Ozanne BW, Stanton PD (1996) Quantitative radioimmunohistochemical measurements of p185(erbB-2) in frozen tissue sections. J Histochem Cytochem 44: 1251-1259

Rice JC, MasseyBrown KS, Futscher BW (1998) Aberrant methylation of the BRCA1 cpg island promoter is associated with decreased BRCA1 mRNA in sporadic breast cancer cells. Oncogene 17: 1807-1812

Robertson KW, Reeves JR, Smith G, Keith WN, Ozanne BW, Cooke TG, Stanton PD (1996) Quantitative estimation of epidermal growth factor receptor and c-erbB-2 in human breast cancer. Cancer Res 56: 3823-3830

Scully R, Chen JJ, Ochs RL, Keegan K, Hoekstra M, Feunteun J, Livingston DM (1997a) Dynamic changes of BRCA1 subnuclear location and phosphorylation state are initiated by DNA damage. Cell 90: 425-435

Scully R, Chen JJ, Plug A, Xiao YH, Weaver D, Feunteun J, Ashley T, Livingston DM (1997b) Association of BRCA1 with Rad51 in mitotic and meiotic cells. Cell 88: $265-275$
Scully R, Ganesan S, Brown M, Decaprio JA, Cannistra SA, Feunteun J, Schnitt S, Livingston DM (1996) Location of BRCA1 in human breast and ovarian cancer cells. Science 272: $123-125$

Thakur S, Zhang HB, Peng Y, Le H, Carroll B, Ward T, Yao J, Farid LM, Couch FJ, Wilson RB, Weber BL (1997) Localization of BRCA1 and a splice variant identifies the nuclear localization signal. Mol Cell Biol 17: $444-452$

Thompson ME, Jensen RA, Obermiller PS, Page DL, Holt JT (1995) Decreased expression of BRCA1 accelerates growth and is often present during sporadic breast cancer progression. Nat Genet 9: 444-450

Wilson CA, Payton MN, Elliott GS, Buaas FW, Cajulis EE, Grosshans D, Ramos L, Reese DM, Slamon DJ, Calzone FJ (1997) Differential subcellular localization, expression and biological toxicity of BRCA1 and the splice variant BRCA1-Delta 11b. Oncogene 14: 1-16

Wilson CA, Payton MN, Pekar TS, Calzone FJ, Reese DM, Slamon DI, Koonin EV, Altschul SF, Bork P, Diamandis EP, Bradley A, Sharan SK, Jensen RA, Thompson ME, Jetton TL et al (1996) BRCA1 protein products: antibody specificity... [1]. Nat Genet 13: $264-272$

Wilson CA, Ramos L, Villasenor MR, Anders KH, Press MF, Clarke K, Karlan B, Chen JJ, Scully R, Livingston D, Zuch RH, Kanter MH, Cohen S, Calzone FJ, Slamon DJ (1999) Localization of human BRCA1 and its loss in high-grade, non-inherited breast carcinomas. Nat Genet 21: $236-240$

Yu X, Wu LJC, Bowcock AM, Aronheim A, Baer R (1998) The c-terminal (BRCT) domains of BRCA1 interact in vivo with ctip, a protein implicated in the ctbp pathway of transcriptional repression. J Biol Chem 273: $25388-25392$ 